\title{
Why go to Tiger Country? A report of two cases of Implanon ${ }^{\circledR}$ removal
}

\author{
Anne M C Webb
}

\section{Case report 1}

A 33-year-old woman who had used Implanon ${ }^{\circledR}$ satisfactorily for 3 years attended for a routine replacement. The insertion had been carried out in the same clinic by an experienced doctor. The patient was slim and the rod was easily palpable over the groove between the biceps and the triceps of the left arm. Under aseptic technique I infiltrated about $1 \mathrm{ml}$ lidocaine 1\% just under the distal end of the rod and gently massaged the area with a gauze to allow the anaesthetic to act. The rod was removed with ease by the 'pop out' technique and a further rod was inserted subdermally through the same incision but slightly more medially. Steri-Strips ${ }^{\circledR}$ and a bandage were applied. About 10 minutes after leaving the patient returned, complaining of numbness and loss of function in her left hand. On examination the left thumb and index finger were warmer than the rest of the hand and their gripping power was reduced. All other movements and sensation in the arm were normal. I explained that her symptoms were probably due to the local anaesthetic effect on a nerve that was close to the previous implant. The effects were compared to dental anaesthesia. I reassured the patient that they would wear off in the next few hours. At follow-up she confirmed that this had indeed happened and that she was happy with her second implant.

\section{Case report 2}

A 22-year-old woman requested removal of an Implanon after 8 months due to prolonged bleeding. It had been inserted in the same clinic by a doctor undergoing training for the Letter of Competence in Subdermal Contraceptive Implant Techniques, supervised by an experienced doctor. The client was thin and the rod was easily palpable over the groove between the biceps and the triceps. Removal was carried out as described in Case 1. During the removal process the patient complained of some tingling over the palmar aspects of her thumb and index finger. She was reassured as in Case 1 and advised to contact the clinic if the symptoms did not settle within a few hours. She seemed happy with this explanation and did not contact the clinic until she required further contraceptive supplies.

J Fam Plann Reprod Health Care 2006; 32(3): 193-194 (Accepted 19 April 2006)

\section{Abacus Clinics for Contraception and Reproductive Health, Liverpool, UK \\ Anne M C Webb, MrCoG, FFFP, Consultant in Family Planning and Reproductive Health Care}

Correspondence to: Dr Anne M C Webb, Abacus Clinics for Contraception and Reproductive Health, 40-46 Dale Street, Liverpool L2 5SF, UK.

E-mail: anne.webb@pct.northliverpool.nhs.uk

\section{Discussion}

When implants were first introduced into the UK the insertion instructions for Norplant ${ }^{\circledR}$ advised insertion in the inner aspect of the arm 6-8 cm above the fold in the elbow. For Implanon, the manufacturers added that the site should be in the groove between the biceps and the triceps (sulcus bicipitalis medialis). They stated that "the chosen site in the arm is one of the few places in the body not easily influenced by weight changes and that the research that went into the siting of the implant was mainly concerning correct anatomical placement to facilitate easy removal. The site was chosen to avoid problems with skin blistering or too deep placement causing damage to neurovascular structures and to limit the risk of migration" (Organon Laboratories Ltd, personal communication).

Correct subdermal placement is essential to aid removal, and problems with removals of deep rods ${ }^{1}$ as well as migration ${ }^{2}$ have been reported. A review of nonmenstrual side effects of implants reported five cases of nerve damage, ${ }^{3}$ and in 1995 a report of the removals from a series of 3000 Norplant insertions recommended insertion over the medial surface of the biceps brachii to avoid possible damage to vital structures. ${ }^{4}$ The siting over the groove was specifically questioned for Norplant. 5

When looking at a cross-section of the arm just below the mid-shaft of the humerus, the median nerve, brachial artery, basilic vein, medial cutaneous nerve of the forearm and the ulnar nerve with accompanying vessels are all in or close to the groove between biceps and triceps (Figure 1 ). Medially and laterally the only structure is muscle. So why should Implanon be inserted at a potentially hazardous site if an alternative site may be safer and just as effective?

If the implant is correctly inserted in the subdermal plane, removal is likely to be straightforward, wherever it is placed, as it will not be affected by weight gain and the implant will be palpable. At removal the local anaesthetic needs to be inserted just deep to the implant as that is where the scalpel is inserted. If there is any slippage of the needle or of the scalpel, any underlying structures could be affected. In most women there is some subcutaneous fat, which provides some safety leeway, but in very slim women, such as those described here, the local anaesthetic could permeate through to the nerves lying close by. This in itself is not a problem, but there is always a chance of the scalpel blade slipping or a sudden movement by the client causing inadvertent deeper penetration.

Is it not somewhat perverse to choose to insert the implant over the neurovascular bundle when the stated aim is to avoid damage to it and when other less risky areas are equally accessible? In clinical practice we occasionally take risks but such risks should be justified and unavoidable. These two cases have strengthened my conviction that inserting Implanon over the groove carries a small but unnecessary risk. Insertion over the triceps feels safer to me, is slightly less visible than over the biceps, and is easy with the client lying down, the elbow flexed and the arm slightly externally rotated. In my view, not going over the groove seems the safer practice to use and to teach unless there is further evidence to the contrary. 


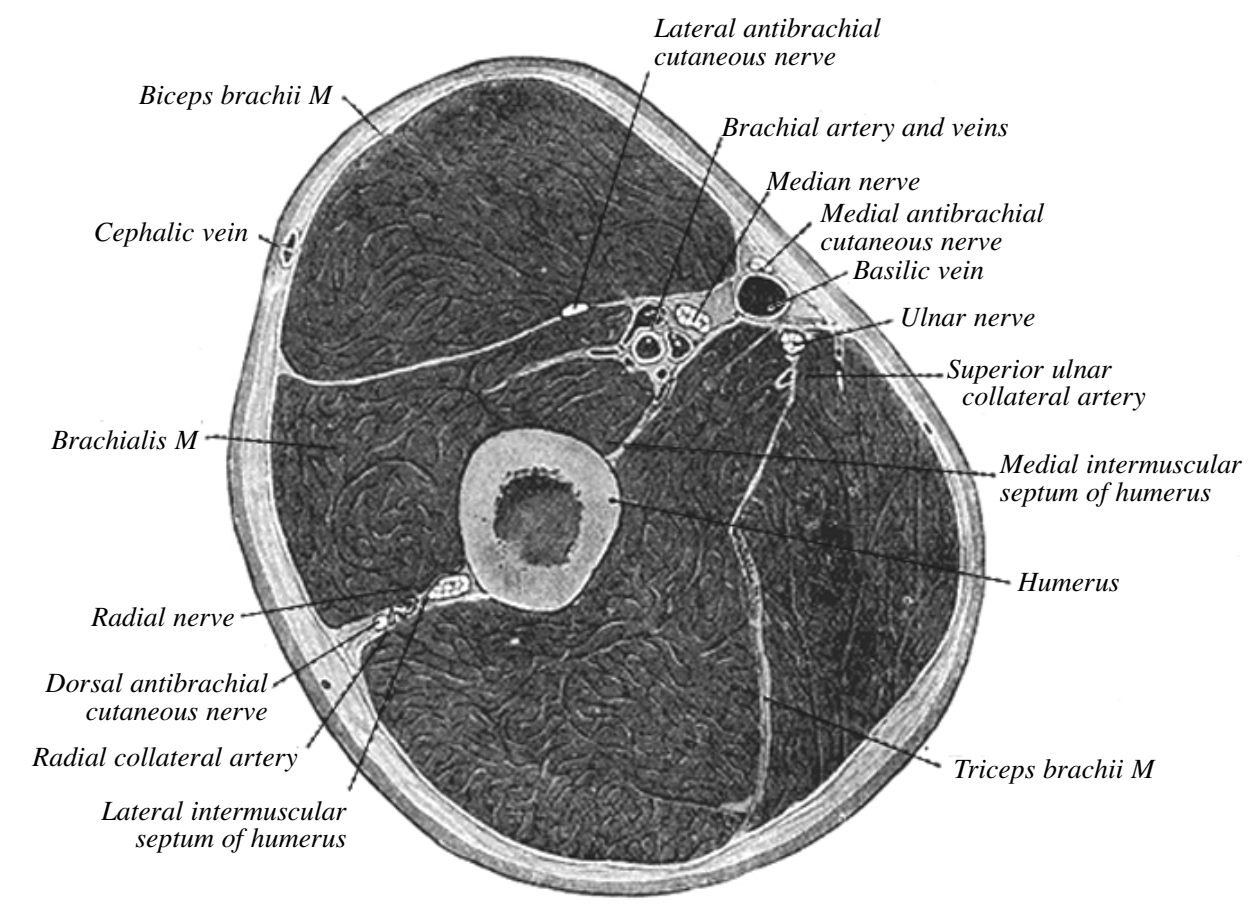

Figure 1 Cross-section through the arm at the level of Implanon ${ }^{\circledR}$ insertion. $M$, muscle. Figure reproduced, with permission, from Gray, Henry, Anatomy of the Human Body, Philadelphia: Lea \& Febiger, 1918; Bartleby.com, 2000. http://www.bartleby.com/107/illus413.html [Accessed 10 April 2006]

Statements on funding and competing interests

Funding. None identified.

Competing interests. None identified.

References

1 Navani M, Robinson C. Clinical challenge with Implanon ${ }^{\circledR}$ removal: a case report. J Fam Plann Reprod Health Care 2005; 31: 161-162.

2 Evans R, Holman R, Lindsay E. Migration of Implanon ${ }^{\circledR}$ : two case reports. J Fam Plann Reprod Health Care 2005; 31: 71-72.
3 Brache V, Faundes A, Alvarez F, Cochon L. Nonmenstrual adverse events during use of implantable contraceptives for women: data from clinical trials. Contraception 2002; 65: 63-74.

4 Sarma SP, Hatcher RP. Neurovascular injury during removal of levonorgestrel implants. Am J Obstet Gynecol 1995; 172: 120-121.

5 Nash C, Staunton T. Focal brachial cutaneous neuropathy associated with Norplant use: suggest careful consideration of the recommended site for inserting contraceptive implants. J Fam Plann Reprod Health Care 2001; 27: 241

\section{HOW TO REGISTER FOR ACCESS TO THE ELECTRONIC JOURNAL}

\section{Registration Process}

1. On connecting with the Faculty website (www.ffprhc.org.uk), click on the picture of the 'Journal' to access the electronic Journal.

2. Next, under Related Links, click on 'Faculty Membership Activation'.

3. In the appropriate boxes enter your Surname, E-mail Address, Country and Membership Number (M000, D000, etc - six digits). NB. These boxes are case-sensitive.

4. Next, select a User Name and Password.

5. Ignore the box marked 'Ingenta Select ID number - CID'.

6. Click on 'Enable Access'.

7. A confirmation e-mail will be sent to you.

\section{After Registration}

Once you have registered you can access the Journal as follows:

1. On connecting with the Faculty website (www.ffprhc.org.uk), click on the picture of the 'Journal' to access the electronic Journal.

2. Select the volume and issue number.

3. Select the article you wish to view.

4. Enter your user name and password. 